\title{
Physician procedure volume and related adverse events after surgically induced abortion: a population-based cohort study
}

\author{
Ning Liu MSc, Simone N. Vigod MD MSc, M. Michèle Farrugia MD MSc, Marcelo L. Urquia PhD, \\ Joel G. Ray MD MSc
}

Cite as: CMAJ 2019 May 13;191:E519-28. doi: 10.1503/cmaj.181288

See related article at www.cmaj.ca/lookup/doi/10.1503/cmaj.190477

\begin{abstract}
BACKGROUND: Induced abortion is a common procedure performed by physicians with varying degrees of clinical experience. We aimed to determine whether a physician's procedure volume influences complications after induced abortion.
\end{abstract}

METHODS: We obtained populationbased retrospective data on surgically induced abortion procedures in Ontario between 2003 and 2015 from Ontario health administrative databases held at ICES. Physician procedure volume was defined as the number of surgically induced abortions performed in the 1-year period preceding the index procedure date, categorized as low $(<10$ th percentile of yearly volume) or higher ( $\geq 10$ th percentile). The primary outcome was a severe adverse event (maternal end organ damage, severe maternal morbidity, intensive care unit admission or death) within 42 days after an induced abortion. The secondary outcome was any adverse event within 42 days.

RESULTS: Among 529141 surgical abortion procedures, we found 850 severe adverse events (1.6 per 1000 procedures, 95\% confidence interval $[\mathrm{Cl}] 1.5-$ 1.7), and 5664 any adverse events (10.7 per 1000 procedures, $95 \% \mathrm{Cl} 10.4-11.0$ ). Severe adverse events occurred in 194 out of 52889 procedures in the lowvolume group (3.7 per 1000 procedures,
95\% Cl 3.2-4.2) compared with 656 out of 476252 procedures in the highervolume group (1.4 per 1000 procedures, $95 \% \mathrm{Cl} 1.3-1.5)$, an adjusted odds ratio (OR) of 1.91 (95\% Cl 1.41-2.59). The odds of any adverse event were also higher in the low-volume versus highervolume group (adjusted OR 1.19, 95\% Cl 1.02-1.40).

INTERPRETATION: Low physician procedure volumes are associated with an elevated risk of a complication after surgically induced abortion. Future investigation should compare processes of care between low- and higher-volume physicians to facilitate quality improvement in abortion care. nduced abortion is a common procedure performed among women of reproductive age. ${ }^{1}$ Although it is technically a simple and safe procedure, complications with different degrees of severity can occur following induced abortion. ${ }^{2-6}$

Physician procedure volume is known to be inversely related to the risk of complications after complex procedures, such as cancer, cardiac and pelvic surgery. ${ }^{7,8}$ In contrast to these complex higher-risk surgeries, surgically induced abortion is a low-risk, less technically demanding procedure, performed mostly among relatively healthy women. In addition, given that most induced abortions are performed for reasons other than a maternal illness or fetal anomaly, such as a mistimed pregnancy or financial burden, ${ }^{9,10}$ this underscores the expectation that the procedure carries little or no risk of an adverse outcome for women. To our knowledge, the influence of physician procedure volume on patient outcomes after induced abortion is not known. Accord- ingly, we aimed to examine the relation between physicians' volume of surgically induced abortion procedures and women's risk of adverse events after surgically induced abortion.

\section{Methods}

\section{Study setting}

We conducted a population-based cohort study using administrative health data for the province of Ontario, Canada, where health care, including access to induced abortion services, is publicly funded. Induced abortions are performed in hospitals, outpatient clinics and health care centres. ${ }^{11}$ In recent years, induced abortions have been increasingly provided at free-standing abortion clinics located almost exclusively in large urban centres. ${ }^{12}$ Up to December 2016, at least $95 \%$ of induced abortions in the province were done as a surgical procedure. $^{3}$ An oral preparation that combines mifepristone and 
misoprostol was approved for induced abortion by Health Canada in July 2015; however, it did not become available until January 2017.13

\section{Sources of data}

We used Ontario health administrative databases held at ICES, Toronto, as described elsewhere $\mathrm{e}^{14,15}$ and detailed in Appendix $1 \mathrm{~A}$, available at www.cmaj.ca/lookup/suppl/doi:10.1503/cmaj.181288/-/ DC1. We linked data sets with procedure-level information using unique encoded patient identifiers and data sets with physician-level information using encoded physician billing numbers.

\section{Study participants}

We included all induced abortions performed in Ontario between Jan. 1, 2003, and Dec. 31, 2015. We defined induced abortion as a termination of pregnancy before 20 weeks' gestation by a surgical procedure or use of an abortifacient pharmaceutical agent that was identified using diagnostic codes and procedure codes (Appendix 1A) from hospital discharges, emergency department visits and physician billing. This approach had a sensitivity of 99.1\% (95\% confidence interval [CI] 98.3-99.6) for identifying induced abortion. ${ }^{16}$ We excluded pharmaceutically induced abortions. We included surgical abortion procedures performed in women aged 15 to 49 years that could be linked to a physician practising in Ontario and that had no missing information for procedure- or physician-level characteristics (Appendix 1B).

\section{Exposures and outcomes}

Our primary study exposure was a physician's volume of surgically induced abortion procedures, defined as the number of surgically induced abortions a physician performed in the 1-year period preceding the index date of the induced abortion. We then ranked the induced abortions included in the analysis based on physicians' procedure volumes and categorized the low-volume group as less than the 10th percentile in volume $(<188$ procedures in the previous year) and the higher-volume group as the 10th percentile or more (>/ 188 procedures in the previous year).

Our primary study outcome was a composite of any severe adverse event within 42 days after a surgical abortion, comprising any severe maternal morbidity, maternal end organ damage, admission to an intensive care unit (ICU) or death. We used a previously published algorithm to identify both maternal end organ damage and severe maternal morbidity. ${ }^{17,18}$ Our secondary outcome was a broader composite of any adverse event within 42 days after an induced abortion, regardless of severity, and included any severe adverse event (as defined above), hemorrhage, retained products of conception, genital tract and pelvic infection, transfusion of red blood cells, damage to pelvic organs and tissues, shock, renal failure, metabolic disorders, venous complications, embolism or other unspecified complications following induced abortion. ${ }^{2,3}$ Adverse events were identified from hospital discharge records or data from emergency department visits (Appendix 1A).

\section{Covariates}

Covariates were considered at the patient or procedure level, and the physician level. At the patient or procedure level, the first domain comprised sociodemographic characteristics of the woman, assessed at the time when the induced abortion was performed, and included her age, rural versus urban residence, neighbourhood income quintile and world region of origin. ${ }^{15}$ The second domain reflected a woman's reproductive history, and included parity and the number of induced abortions she had before the index procedure. The third domain evaluated a woman's pre-existing health conditions in the 2 years preceding the date of the index procedure, denoted by the number of Johns Hopkins Aggregated Diagnosis Groups. ${ }^{19}$ The fourth domain characterized the index procedure and included when the procedure was performed (early [ $<15 \mathrm{wk}$ gestation] or late [ $\geq 15 \mathrm{wk}$ gestation]), location (within or outside of hospital) and the year of the procedure.

Physician-level covariates included sex, place of training, years in practice and specialty (obstetrics-gynecology, family medicine or other).

\section{Statistical analysis}

We calculated event rates (per 1000 procedures) for the primary and secondary outcomes among the entire cohort and then by deciles of physician procedure volume. The latter suggested that, in the bottom decile, the risk of severe adverse events was much higher than in the rest of the deciles (Figure 1), so we set a "low procedure volume" at less than the 10th percentile.

We reported procedure- and physician-level covariates according to whether the procedure was performed by a physician with a low ( $<10$ th percentile) or higher ( $\geq 10$ th percentile) procedure volume. We compared means and proportions using standardized differences, with an absolute value 0.10 or more indicating meaningful difference. ${ }^{20}$

To assess the appropriateness of using the 10th percentile cut point to define the low and higher physician procedure volume, we used Analysis 1 (Appendix 1C) to model physician procedure volume as a continuous variable and used fractional polynomial methods to select the best-fitting transformation of this variable for describing its relation with both severe and any adverse event. ${ }^{21}$

In Analysis 2 (the main model), we used generalized estimating equations with binomial distribution, logit link, exchangeable correlation structure and robust standard errors, to produce odds ratios (ORs) and 95\% Cls for having an adverse event within 42 days after induced abortion, comparing the low-volume group to the higher-volume group (the referent), adjusting for all covariates and further accounting for multiple procedures clustered within the same physician..$^{22,23}$

We performed Analyses 3-8 to test the robustness of the findings from the main model (Appendix 1C).

We also conducted a sequence of multilevel logistic regression models with physician-level random effects to explore further the heterogeneity for adverse events between different physicians, and variation in rates of adverse events between physicians explained by patient- or procedure-level and physician-level characteristics ${ }^{24}$ (Analyses 9 and 10 in Appendix 1C).

We performed the analysis using SAS version 9.4 (SAS Institute).

\section{Ethics approval}

Ethics approval was granted by the Research Ethics Board of Sunnybrook Health Sciences Centre and the Office of Research Ethics at the University of Toronto. 


\section{Results}

We found that 565631 induced abortions were performed in Ontario between 2003 and 2015. Of these, 13286 were pharmaceutically induced abortions, 16655 could not be linked to an Ontario physician and 5308 had missing information. Our final sample comprised 529141 surgically induced abortion procedures (Appendix 1B).

There were 850 severe adverse events (1.6 per 1000 procedures, 95\% $\mathrm{Cl} 1.5-1.7)$ and 5664 any adverse events (10.7 per 1000 , 95\% Cl 10.4-11.0) (Table 1). There were 28 deaths; of the 23 deaths with a known cause, most were due to intentional

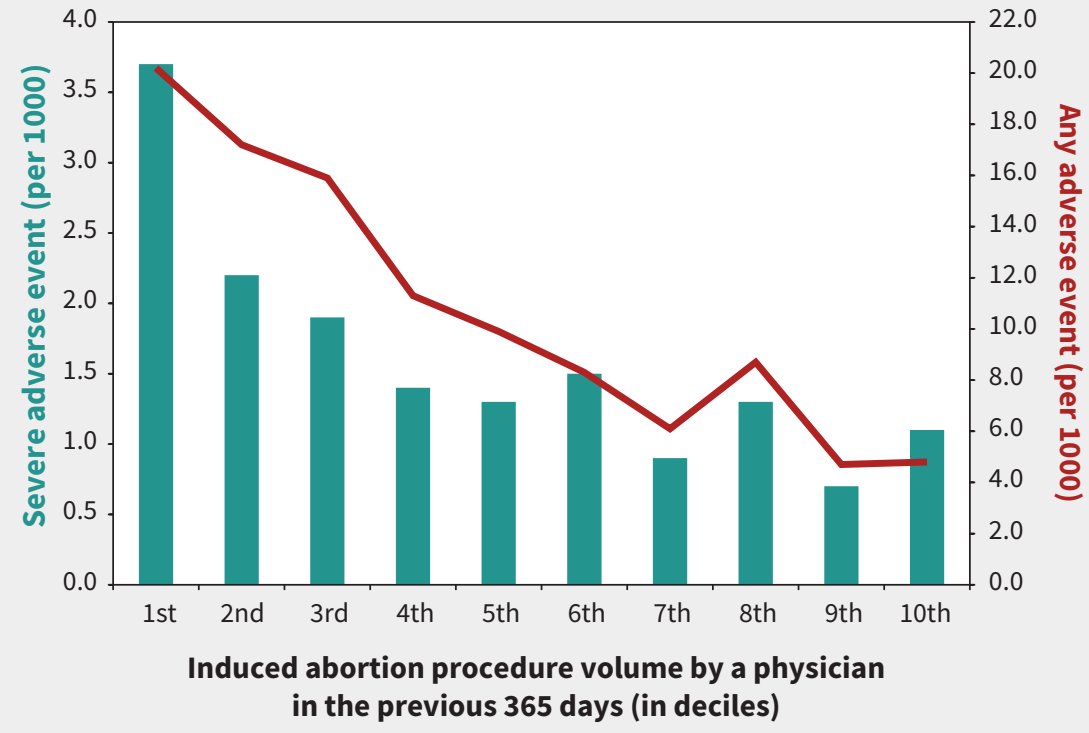

Figure 1: Incidence of an adverse event within 42 days after a surgically induced abortion procedure according to physician volume of surgically induced abortion procedures in the previous year. The green bars and the left axis show the rate of severe adverse events (Table 1). The red line and right axis show the rate of any adverse event, regardless of severity (Table 1). Procedure volume ranges from lowest (1st decile) to highest (10th decile).

\section{Table 1: Rate of adverse events within 42 days after a surgically induced abortion, by severe and any adverse events}

\begin{tabular}{|c|c|c|}
\hline Type of adverse event & $\begin{array}{l}\text { No. }(\%) \text { of procedures with an } \\
\text { adverse event } \\
n=529141\end{array}$ & $\begin{array}{l}\text { Rate of adverse events per } \\
1000 \text { procedures }(95 \% \mathrm{CI}) \\
\qquad n=529141\end{array}$ \\
\hline Severe adverse event ${ }^{\star}$ & $850(0.2)$ & $1.6(1.5-1.7)$ \\
\hline Severe maternal morbidity & $550(0.1)$ & $1.0(1.0-1.1)$ \\
\hline Maternal end organ damage & $221(0.0)$ & $0.4(0.4-0.5)$ \\
\hline Intensive care unit admission & $165(0.0)$ & $0.3(0.3-0.4)$ \\
\hline Death & $28(0.0)$ & $0.05(0.03-0.07)$ \\
\hline Any adverse event $\dagger$ & $5664(1.1)$ & $10.7(10.4-11.0)$ \\
\hline Severe adverse event & $850(0.2)$ & $1.6(1.5-1.7)$ \\
\hline Hemorrhage & $2175(0.4)$ & $4.1(3.9-4.3)$ \\
\hline Retained products of conception & $1583(0.3)$ & $3.0(2.8-3.1)$ \\
\hline Infection & $656(0.1)$ & $1.2(1.1-1.3)$ \\
\hline Transfusion of red blood cells & $256(0.0)$ & $0.5(0.4-0.5)$ \\
\hline Other $\ddagger$ & $1059(0.2)$ & $2.0(1.9-2.1)$ \\
\hline
\end{tabular}


Table 2 (part 1 of 2): Characteristics of surgically induced abortion procedures, patients and physicians who performed the procedure, categorized by low (< 10th percentile) and higher ( $\geq 10$ th percentile) physician induced-abortion volume in the previous year

Characteristic

\section{IA procedure}

Patient age, yr

Mean \pm SD

$<20$

$20-24$

$25-29$

30-34

35-39

$\geq 40$

Rural residence

Neighbourhood income quintile

Q1 (lowest)

Q2

Q3

Q4

Q5 (highest)

World region of origin

\begin{tabular}{l} 
Canada \\
Africa \\
Caribbean \\
East Asia \\
Hispanic America \\
Middle East \\
South Asia \\
Western $f$ \\
Nulliparous \\
No. of previous IAs \\
0 \\
1 \\
2 \\
$\geq 3$ \\
Total no. of adjusted ADGs \\
Median (IQR) \\
$0-2$ \\
$3-4$ \\
$5-6$ \\
$\geq 7$ \\
\hline
\end{tabular}

Gestational age at IA, wk

Early $\mid A<15 w k$

Late $I A \geq 15 w k$
No. $(\%)^{\star}$ of physician IA procedure volume ( $<10$ th percentile) ( $n=52889)$

$26.9 \pm 7.2$
$8414(15.9)$
$15091(28.5)$
$11034(20.9)$
$8581(16.2)$
$6639(12.6)$
$3130(5.9)$
$5951(11.3)$

$17682(33.4)$

$12120(22.9)$

$9180(17.4)$

7740 (14.6)

$6167(11.7)$

40835 (77.2)

$1168(2.2)$

$1297(2.5)$

3648 (6.9)

$1080(2.0)$

$884(1.7)$

$2560(4.8)$

$1417(2.7)$

25495 (48.2)

31288 (59.2)

$11678(22.1)$

4982 (9.4)

$4941(9.3)$

$$
5(3-7)
$$

11734 (22.2)

$13657(25.8)$

$12872(24.3)$

$14626(27.7)$

$50853(96.2)$

2036 (3.8)
No. (\%)* of physician IA procedure volume ( $\geq 10$ th percentile) ( $n=476252$ )

Standardized difference $\dagger$ 
Table 2 (part 2 of 2): Characteristics of surgically induced abortion procedures, patients and physicians who performed the procedure, categorized by low (<10th percentile) and higher ( $\geq 10$ th percentile) physician induced-abortion volume in the previous year

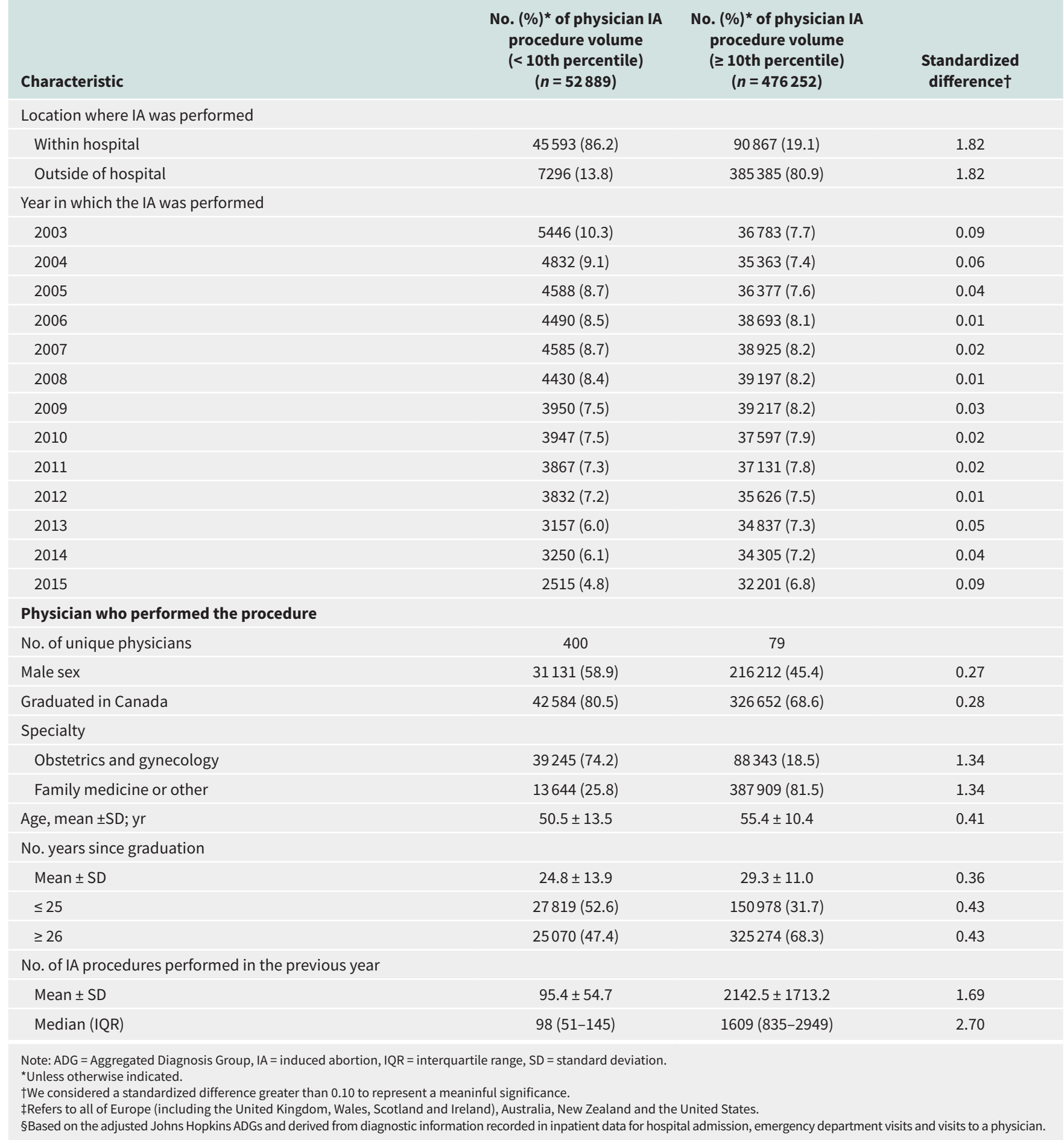

self-harm or assault. The rate of a severe adverse event was 3.7 per 1000 procedures $(95 \% \mathrm{Cl} 3.2-4.2)$ at the lowest volume decile (median number of procedures 98 , interquartile range [IQR] 51-145; maximum number of procedures 188), rapidly declining by the next higher volume decile (Figure 1 ). For any adverse event, the rate was 20.2 per 1000 procedures (95\% Cl 19.0-21.4) at the lowest decile, which gradually declined at each higher decile (Figure 1).

The probability of a woman having a severe adverse event rapidly declined with increasing physician procedure volume and started to plateau after her physician's procedure volume surpassed about 200 procedures (Analysis 1, Appendix 1D), which 
Table 3: Odds of having a severe or any adverse event within $\mathbf{4 2}$ days after a surgically induced abortion in relation to the volume of surgically induced abortion procedures performed by that physician in the preceding year being less than the 10th versus the 10th percentile or more (Analysis 2, main model)

\begin{tabular}{|c|c|c|c|c|c|c|}
\hline Outcome & $\begin{array}{l}\text { Physician } \\
\text { surgical IA } \\
\text { procedure } \\
\text { volume }\end{array}$ & $\begin{array}{l}\text { No. }(\%) \text { of } \\
\text { women with an } \\
\text { adverse } \\
\text { outcome }\end{array}$ & $\begin{array}{l}\text { Event rate per } \\
1000 \text { procedures } \\
(95 \% \mathrm{Cl})\end{array}$ & $\begin{array}{l}\text { Crude OR } \\
(95 \% \mathrm{Cl})^{\star}\end{array}$ & $\begin{array}{l}\text { Adjusted OR not } \\
\text { accounting for } \\
\text { clustering effect } \\
(95 \% \mathrm{Cl}) \dagger\end{array}$ & $\begin{array}{c}\text { Adjusted OR } \\
\text { accounting for } \\
\text { clustering effect } \\
(95 \% \mathrm{Cl}) \neq\end{array}$ \\
\hline \multirow[t]{2}{*}{$\begin{array}{l}\text { Severe adverse } \\
\text { event§ }\end{array}$} & $\begin{array}{c}\geq 10 \text { th percentile } \\
n=476252\end{array}$ & $656(0.1)$ & $1.4(1.3-1.5)$ & 1.00 (Ref) & 1.00 (Ref) & 1.00 (Ref) \\
\hline & $\begin{array}{c}<10 \text { th percentile } \\
n=52889\end{array}$ & $194(0.4)$ & $3.7(3.2-4.2)$ & $2.67(2.27-3.13)$ & $1.94(1.60-2.34)$ & $1.91(1.41-2.59)$ \\
\hline \multirow[t]{2}{*}{ Any adverse event $₫$} & $\begin{array}{c}\geq 10 \text { th percentile } \\
n=476252\end{array}$ & $4596(1.0)$ & $9.7(9.4-9.9)$ & 1.00 (Ref) & 1.00 (Ref) & 1.00 (Ref) \\
\hline & $\begin{array}{c}<10 \text { th percentile } \\
n=52889\end{array}$ & $1068(2.0)$ & $20.2(19.0-21.4)$ & $2.12(1.98-2.26)$ & $1.43(1.32-1.54)$ & $1.19(1.02-1.40)$ \\
\hline
\end{tabular}

Note: $\mathrm{ADG}=$ Aggregated Diagnosis Group, $\mathrm{Cl}=$ confidence interval, $\mathrm{IA}=$ induced abortion, $\mathrm{ICU}=$ intensive care unit, $\mathrm{OR}=$ odds ratio, $\mathrm{Ref}=$ referent.

${ }^{\star}$ Results from univariable logistic regression models.

†Results from multivariable logistic regression models, adjusted for women's age, rural or urban residence, neighbourhood income quintile, world region of origin, nulliparous status, number of previous IAs, total number of adjusted ADGs in the 2 years before the index IA, gestational age and year when the IA was performed, sex of the physician, physician specialty and number of years since the physician graduated.

$\ddagger$ Results from multivariable logistic regression models, with generalized estimating equations applied to account for multiple IA procedures clustered within the same physician. Adjusted for women's age, rural or urban residence, neighbourhood income quintile, world region of origin, nulliparous status, number of previous IAs, total number of adjusted ADGs in the 2 years before the index IA, gestational age and year when the IA was performed, sex of the physician, physician specialty and number of years since the physician graduated. $\S C o m p r i s e s$ any of the following: maternal end organ damage, severe maternal morbidity, admission to ICU or death.

ฯ Comprises any of the following: hemorrhage, infection, retained products of conception, other, transfusion of red cell bloods, maternal end organ damage, severe maternal morbidity, admission to ICU or death.

was in alignment with the 10th percentile cut point of 188 procedures in the previous year. For any adverse event, we found a similar rapid decline after about 150 previous procedures (Analysis 1 , Appendix 1E).

Four hundred unique physicians performed 52889 procedures in the low-volume group, and 79 physicians completed 476252 procedures in the higher-volume group. Compared with procedures in the higher-volume group, we found that procedures in the low-volume group were more likely to be performed within hospital, by a male physician, a graduate of a Canadian medical school and an obstetrician-gynecologist (Table 2).

A severe adverse event occurred in 194 out of 52889 procedures in the low-volume group (3.7 per 1000 procedures, $95 \% \mathrm{Cl}$ 3.2-4.2) compared with 656 out of 476252 procedures in the higher-volume group (1.4 per 1000 procedures, $95 \% \mathrm{Cl} 1.3-1.5$ ) an adjusted OR of 1.91 (95\% Cl 1.41-2.59) (Analysis 2, Table 3). For any adverse event, the corresponding adjusted OR was 1.19 (95\% Cl 1.02-1.40) (Analysis 2, Table 3). Results were similar when we restricted the analysis to 528295 procedures performed by physicians practicing in Ontario for the 1-year period before the index procedure date (Analysis 3, Appendix 1F).

In stratified analyses, we found that the association of low volume of surgical abortions with severe adverse events observed in the main model was generally preserved and was more pronounced for late versus early induced abortion (adjusted OR 5.35, 95\% Cl 2.80-8.93 v. 1.64, 95\% Cl 1.19-2.26, respectively; $p$ for interaction $<0.001$ ) (Analysis 4a, Figure 2 ). Association of low volume of surgical abortions with any adverse event was more profound for late versus early induced abortion (adjusted OR 2.95, 95\% Cl 1.67-5.21 v. 1.10, 95\% Cl 0.93-1.31, respectively; $p$ for interaction $<0.001$ ) and for procedures performed by an obstetrician-gynecologist versus a family physician or other specialist (adjusted OR 1.29, 95\% Cl 1.12-1.49 v. $0.94,95 \% \mathrm{Cl} 0.64-1.39$, respectively; $p$ for interaction $=0.03$ ) (Analysis 4b, Figure 3).

The adjusted OR for severe adverse events rose to 2.50 (95\% $\mathrm{Cl} 1.80-3.46$ ) at less than the 5 th percentile (median number of procedures 51, IQR 20-74), as did the adjusted OR for any adverse event (1.43, 95\% Cl 1.20-1.70) (Analysis 5, Appendix 1G). A dose-response effect was also seen at the broader thresholds of less than the 10th, or 10th to 19th, versus the 20th percentile or more, although less so for any adverse event (Analysis 6, Appendix $1 \mathrm{H})$.

Women who had an induced abortion performed by a physician with a persistently low volume had the highest adjusted OR of having a severe adverse event $(2.06,95 \% \mathrm{Cl} 1.48-2.86)$ or any adverse event (1.30, 95\% Cl 1.09-1.56) (Analysis 7, Appendix 1I).

There were 13778 women who had 1 abortion performed by a low-volume physician and another by a higher-volume physician. Comparing the former to the latter, the adjusted OR was 1.51 (95\% Cl 0.90-2.52) for a severe adverse event and $1.25(95 \% \mathrm{Cl}$ 1.04-1.50) for any adverse event (Analysis 8, Appendix $1 \mathrm{~J}$ ).

We found that the multilevel logistic regression model that included physician-specific random effects and procedure-level characteristics explained $38.4 \%$ of the variation in rates of severe adverse events between physicians and reduced the median OR from $3.44(95 \% \mathrm{Cl} 2.64-4.28)$ in the model considering only physician-specific random effects to 2.64 (95\% Cl 2.07-3.20) (Analysis 9, Appendix 1K). When we added physician-level characteristics, this accounted for another $25.0 \%$ of the variation and further reduced the median OR to 2.11 (95\% 1.69-2.51) (Analysis 9, Appendix 1K). 


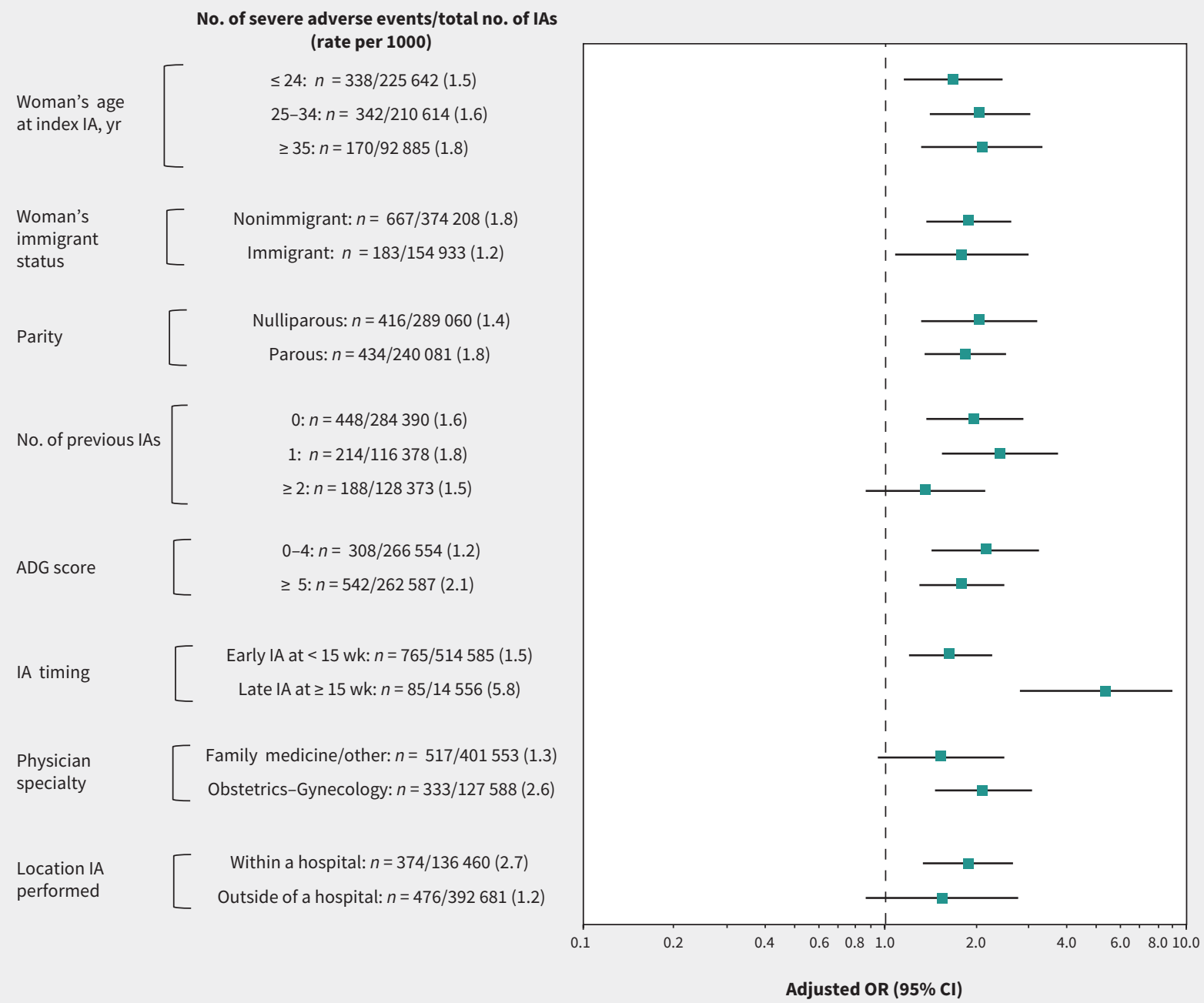

Figure 2: Stratification of the main model by age, immigrant status, parity, number of previous induced abortions (IAs), comorbidity, timing of the IA, physician specialty and location where the IA was performed, presenting the odds of having a severe adverse event (Table 1 ) within 42 days after a surgically IA performed by a physician whose procedure volume in the previous year was $<10$ th versus $\geq 10$ th percentile (the referent) (Analysis $4 a$ ). Odds ratios (ORs) were adjusted for age, rural or urban residence, neighbourhood income quintile, world region of origin, nulliparous status, number of previous IAs, total number of adjusted Aggregated Diagnosis Groups (ADGs) in the 2 years before the index IA, gestational age and year when the IA was performed, sex of the physician, physician specialty and number of years since the physician graduated. The interaction term between physician procedure volume and the timing of IA was statistically significant $(p<0.001)$. Note: $\mathrm{Cl}=$ confidence interval.

For any adverse event, adjusting for both procedure-level and physician-level characteristics explained only $36.8 \%$ of the variation between physicians (Analysis 10, Appendix 1L).

\section{Interpretation}

In Ontario, we found that women who had an induced abortion performed surgically by a physician with a low procedure volume of less than the 10th percentile had almost double the odds of having a severe adverse event within 42 days of the procedure. For any adverse event, the associated odds were about $20 \%$ greater in the low-volume group.
As we expected, the rate of adverse events in this study was much lower than that observed in settings with limited access to safe abortion services ${ }^{25}$ or in studies using a broader range of diagnoses in counting adverse events. ${ }^{26}$ The median OR in the physician-level random-effects model, interpreted as a median relative difference of 2.11 times in the odds of having a severe adverse event when comparing an identical procedure performed by a higher-risk physician to that of a lower-risk physician, suggested large heterogeneity in rates of severe adverse events between different physicians.

We found that the effect of physician volume on adverse events was more profound for procedures done at 15 weeks 
No. of any adverse events/total no. of IAs (rate per 1000)

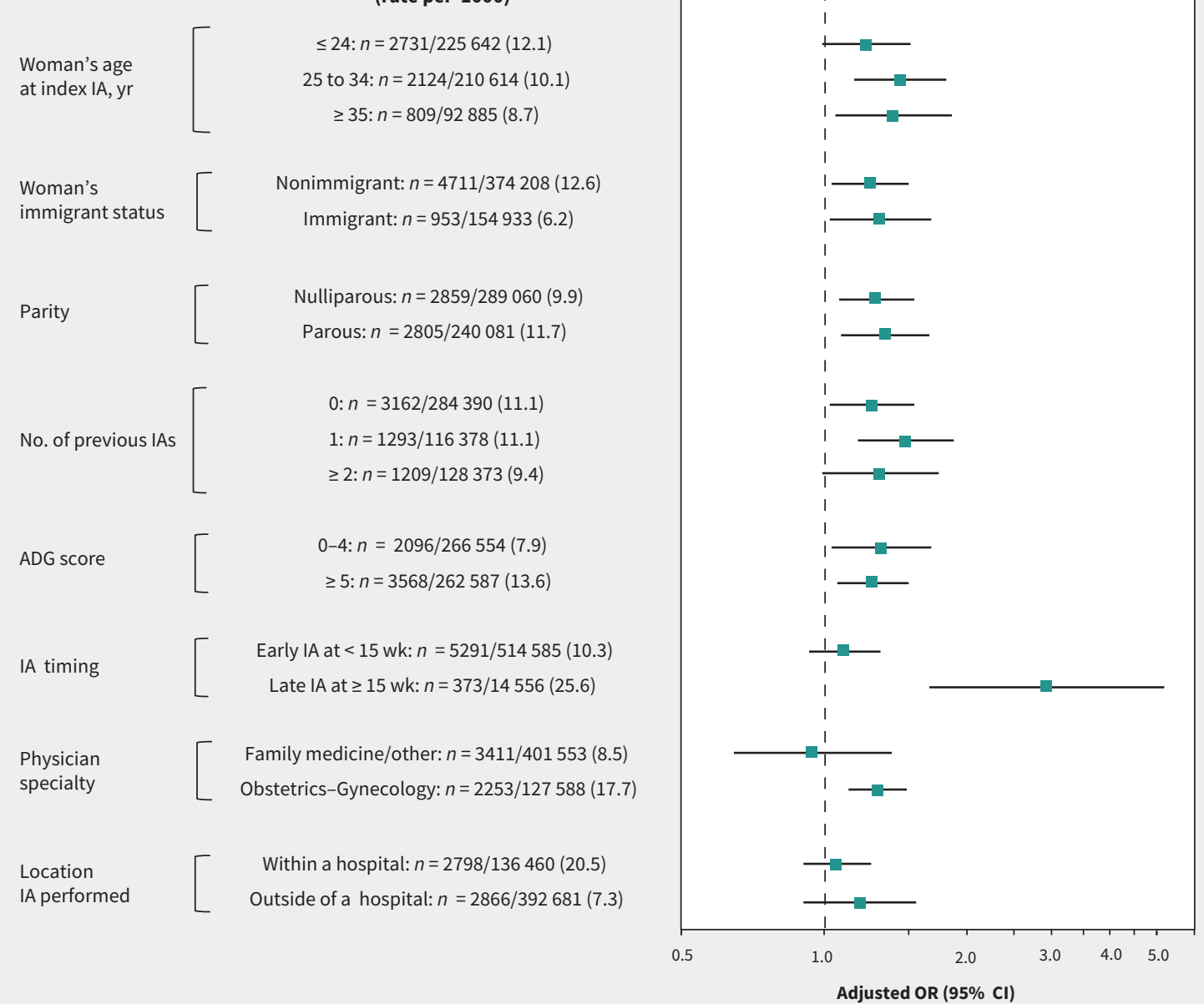

Figure 3: Stratification of the main model by age, immigrant status, parity, number of previous induced abortion (IA), comorbidity, timing of the IA, physician specialty and location where the IA was performed, presenting the odds of having any adverse event, regardless of severity (Table 1 ) within 42 days after a surgically IA performed by a physician whose procedure volume in the previous year was $<10$ th versus $\geq 10$ th percentile (the referent) (Analysis 4b). Odds ratios (ORs) were adjusted for age, rural or urban residence, neighbourhood income quintile, world region of origin, nulliparous status, number of previous IAs, total number of adjusted Aggregated Diagnosis Groups (ADGs) in the 2 years before the index IA, gestational age and year when the IA was performed, sex of the physician, physician specialty and number of years since the physician graduated. The interaction terms between physician procedure volume and the timing of induced abortion $(p<0.001)$, and between physician procedure volume and physician specialty $(p=0.03)$, were both significant. Note: $\mathrm{Cl}=$ confidence interval.

gestation or later as well as those performed by an obstetrician-gynecologist. This may be because later procedures are more complex, and the technical skills of the physician may have a larger influence on procedure outcome.

Our study lacked information on direct processes of care, including clinical decision-making, procedural techniques and the availability of allied health care, each of which may contribute to the observed relation between volume and outcome. ${ }^{27}$ Nevertheless, a physician with greater procedure volume likely gains procedural proficiency, and an improved ability to recognize and manage periprocedural complications. ${ }^{28}$ Higher-volume physicians may be more likely to be surrounded by a more experienced team of other health care providers and to work in settings with procedure-specific guidelines and protocols for induced abortion. ${ }^{29,30}$ Together, these factors may contribute to differences in rates of adverse events between low- and highervolume physicians.

\section{Limitations}

Our study has several limitations. There was no information about the reasons why women underwent an induced abortion: maternal health status after an induced abortion for fetal anomalies might differ from that performed for social reasons. ${ }^{9,10}$ Because we observed the volume-outcome relation in both 
early and late induced abortion and early induced abortion typically precedes the gestational period of screening for structural anomalies, ${ }^{31}$ our findings were unlikely to be materially confounded by this issue. As the relative odds for severe adverse events in the low-volume physician group was more pronounced for induced abortion done within a hospital, it is possible that administration of anesthesia was a residual confounder. We also lacked details about previous cesarean delivery or body mass index, both of which may influence outcomes after induced abortion. ${ }^{32,33}$

We created composite adverse event outcomes. Although previously used in other studies, ${ }^{17,18}$ not all conditions that comprise the composite outcomes have been validated. Despite evident differences in the occurrence of the individual components of the composite outcomes, multiple models for each individual type of adverse event were not feasible. In addition, findings from our study may not be applicable to pharmaceutically induced abortions.

\section{Conclusion}

Low physician volume of surgically induced abortion procedures was associated with an increased risk of adverse events among women undergoing these procedures. These findings offer support to the current centralization of induced abortion procedures within urban abortion clinics, performed by highervolume physicians. ${ }^{11}$ However, centralization would be expected to limit access further to induced abortion, particularly in rural areas. Given that serious adverse events after induced abortion are uncommon, any focus on centralization should also consider geographical access to the procedure and patient wait times. Adverse events vary widely between physicians and are only partly explained by physician volumes. Therefore, quality improvement efforts should seek to identify the most influential processes of care related to adverse events after induced abortion and optimize ways to improve those processes, especially among low-volume practitioners. $^{34}$

\section{References}

1. Sedgh G, Bearak J, Singh S, et al. Abortion incidence between 1990 and 2014: global, regional, and subregional levels and trends. Lancet 2016;388:258-67.

2. Taylor D, Upadhyay UD, Fjerstad M, et al. Standardizing the classification of abortion incidents: the Procedural Abortion Incident Reporting and Surveillance (PAIRS) Framework. Contraception 2017;96:1-13.

3. Induced abortions reported in Canada in 2016. Ottawa: Canadian Institute for Health Information; 2018. Available: www.cihi.ca/en/induced-abortions -reported-in-canada-in-2016 (accessed 2019 Apr. 15).

4. Adler AJ, Filippi V, Thomas SL, et al. Incidence of severe acute maternal morbidity associated with abortion: a systematic review. Trop Med Int Health 2012;17:177-90.

5. Fawcus SR. Maternal mortality and unsafe abortion. Best Pract Res Clin Obstet Gynaecol 2008;22:533-48.

6. Haddad LB, Nour NM. Unsafe abortion: unnecessary maternal mortality. Rev Obstet Gynecol 2009;2:122-6.

7. Birkmeyer JD, Stukel TA, Siewers AE, et al. Surgeon volume and operative mortality in the United States. N Engl J Med 2003;349:2117-27.
8. Sung VW, Rogers ML, Myers DL, et al. Impact of hospital and surgeon volumes on outcomes following pelvic reconstructive surgery in the United States. Am J Obstet Gynecol 2006;195:1778-83.

9. Chae S, Desai S, Crowell M, et al. Reasons why women have induced abortions: a synthesis of findings from 14 countries. Contraception 2017;96:233-41.

10. Kirkman M, Rowe $\mathrm{H}$, Hardiman A, et al. Reasons women give for abortion: a review of the literature. Arch Womens Ment Health 2009;12:365-78.

11. Sabourin JN, Burnett M. A review of therapeutic abortions and related areas of concern in Canada. J Obstet Gynaecol Can 2012;34:532-42.

12. Norman WV, Soon JA, Maughn N, et al. Barriers to rural induced abortion services in Canada: findings of the British Columbia Abortion Providers Survey (BCAPS). PLoS One 2013;8:e67023.

13. Grant K. Long awaited abortion pill Mifegymiso makes Canadian debute. The Globe and Mail [Toronto] 2017 Jan. 20. Available: www.theglobeandmail.com/ news/national/long-awaited-abortion-pill-mifegymiso-rolls-out-in-canada/ article33695167/ (accessed 2018 Sept. 3).

14. Liu N, Farrugia MM, Vigod SN, et al. Intergenerational abortion tendency between mothers and teenage daughters: a population-based cohort study. CMAJ 2018;190:E95-102.

15. Liu N, Vigod SN, Farrugia MM, et al. Venous thromboembolism after induced abortion: a population-based, propensity-score-matched cohort study in Canada. Lancet Haematol 2018;5:e279-88.

16. Samiedaluie S, Peterson S, Brant R, et al. Validating abortion procedure coding in Canadian administrative databases. BMC Health Serv Res 2016;16:255.

17. Joseph KS, Fahey J; Canadian Perinatal Surveillance System. Validation of perinatal data in the Discharge Abstract Database of the Canadian Institute for Health Information. Chronic Dis Can 2009;29:96-100.

18. Metcalfe A, Lix LM, Johnson JA, et al. Validation of an obstetric comorbidity index in an external population. BJOG 2015;122:1748-55.

19. The Johns Hopkins ACG ${ }^{\circledR}$ System Version 10.0. Available: www.hopkinsacg.org/ document/acg-system-version-10-0-technical-reference-guide/ (accessed 2017 Dec. 8).

20. Mamdani M, Sykora K, Li P, et al. Reader's guide to critical appraisal of cohort studies: 2. Assessing potential for confounding. BMJ 2005;330:960-2.

21. Royston P, Sauerbrei W. Building multivariable regression models with continuous covariates in clinical epidemiology - with an emphasis on fractional polynomials. Methods Inf Med 2005;44:561-71.

22. Liang KY, Zeger SL. Longitudinal data analysis using generalized linear models. Biometrika 1986;73:13-22.

23. Hubbard AE, Ahern J, Fleischer NL, et al. To GEE or not to GEE: comparing population average and mixed models for estimating the associations between neighborhood risk factors and health. Epidemiology 2010;21:467-74.

24. Austin PC, Merlo J. Intermediate and advanced topics in multilevel logistic regression analysis. Stat Med 2017;36:3257-77.

25. Calvert C, Owolabi OO, Yeung F, et al. The magnitude and severity of abortionrelated morbidity in settings with limited access to abortion services: a systematic review and meta-regression. BMJ Glob Health. 2018;3:e000692.

26. Roberts SCM, Upadhyay UD, Liu G, et al. Association of facility type with procedural-related morbidities and adverse events among patients undergoing induced abortions. JAMA 2018;319:2497-506.

27. Halm EA, Lee C, Chassin MR. Is volume related to outcome in health care? A systematic review and methodologic critique of the literature. Ann Intern Med 2002;137:511-20.

28. Anger JT, Rodriguez LV, Wang Q, et al. The role of provider volume on outcomes after sling surgery for stress urinary incontinence. J Urol 2007;177:145762, discussion 1462 .

29. Gfrerer L, Mattos D, Mastroianni M, et al. Assessment of patient factors, surgeons, and surgeon teams in immediate implant-based breast reconstruction outcomes. Plast Reconstr Surg 2015;135:245e-52e. 
30. Birkmeyer JD, Sun Y, Goldfaden A, et al. Volume and process of care in highrisk cancer surgery. Cancer 2006;106:2476-81.

31. Audibert F, De Bie I, Johnson JA, et al. No. 348-Joint SOGC-CCMG guideline: update on prenatal screening for fetal aneuploidy, fetal anomalies, and adverse pregnancy outcomes. J Obstet Gynaecol Can 2017;39:805-17.

32. Mark KS, Bragg B, Talaie T, et al. Risk of complication during surgical abortion in obese women. Am J Obstet Gynecol 2018;218:238.e1-238.e5.
33. Guiahi M, Schiller G, Sheeder J, et al. Safety of first-trimester uterine evacuation in the outpatient setting for women with common chronic conditions. Contraception 2015;92:453-7.

34. Urbach DR. Pledging to eliminate low-volume surgery. N Engl J Med 2015;373: 1388-90.

\section{Competing interests: None declared.}

This article has been peer reviewed.

Affiliations: Institute of Health Policy Management and Evaluation (Liu, Vigod, Ray), University of Toronto; ICES (Liu, Vigod, Urquia, Ray); Women's College Hospital and Department of Psychiatry (Vigod), University of Toronto; Mount Sinai Hospital (Farrugia); Department of Obstetrics and Gynaecology (Farrugia), University of Toronto; Dalla Lana School of Public Health (Urquia), University of Toronto; Departments of Medicine, and Obstetrics and Gynecology (Ray), St. Michael's Hospital, Toronto, Ont.; Manitoba Centre for Health Policy (Urquia), Department of Community Health Sciences, Rady Faculty of Health Sciences, University of Manitoba, Winnipeg, Man.

Contributors: Ning Liu and Joel Ray conceived and designed the study. Ning Liu had full access to all of the data in the study and takes responsibility for the integrity of the data and the accuracy of the data analysis. Ning Liu and Joel Ray acquired the data and performed statistical analysis. Ning Liu and Joel Ray drafted the manuscript. Simone Vigod, M. Michèle Farrugia and Marcelo Urquia contributed to study design. Simone Vigod, M. Michèle Farrugia and Marcelo Urquia contributed to statistical analysis and the interpretation of data. All of the authors provided critical revision of the manuscript for important intellectual content, gave final approval of the veriion to be published and agreed to be accountable for all aspects of the work.

Funding: Joel Ray is supported by an Applied Research Chair in Reproductive and Child Health Services and Policy Research from the Canadian Institutes of Health Research. Marcelo Urquia is supported by a Canada Research Chair in Applied Population Health.

Data sharing: ICES is named as a prescribed entity under Section 45(1) of Ontario's Personal Health Information Protection Act, 2004 (PHIPA). As a requirement of having this status in PHIPA, ICES policies, practices and procedures are reviewed and approved by the Ontario Information and Privacy Commissioner. Access to raw data is governed by confidentiality agreements between ICES and independent investigators as per PHIPA guidelines.

Acknowledgement: The authors thank Dr. Michael Geary, St. Michael's Hospital,
Toronto, Ont., for his valuable suggestions for the study design.

Disclaimer: This study was supported by ICES, which is funded by an annual grant from the Ontario Ministry of Health and Long-Term Care (MOHLTC). The opinions, results and conclusions reported in this paper are those of the authors and are independent from the funding sources. No endorsement by ICES or the Ontario MOHLTC is intended or should be inferred. Parts of this material are based on data and information compiled and provided by the Canadian Institute for Health Information (ClHI). However, the analyses, conclusions, opinions and statements expressed herein are those of the authors, and not necessarily those of $\mathrm{CIHI}$. The funders had no role in the design and conduct of the study; collection, management, analysis, and interpretation of the data; preparation, review, or approval of the manuscript; and decision to submit the manuscript for publication.

Accepted: Apr. 3, 2019

Correspondence to: Joel Ray, rayj@smh.ca 